\title{
Short- and medium-term car registration forecasting based on selected macro and socio-economic indicators in European countries
}

\author{
Lubor Homolka $^{\mathrm{a}, *}, \mathrm{Vu}$ Minh Ngo ${ }^{\mathrm{a}}$, Drahomíra Pavelková ${ }^{\mathrm{a}}$, Bach Tuan Le ${ }^{\mathrm{a}}$, Bruce Dehning ${ }^{\mathrm{b}}$ \\ ${ }^{a}$ Tomas Bata University in Zlín, Faculty of Management and Economics, Nám. TGM 5555, 760 01, Zlín, Czech Republic \\ ${ }^{\mathrm{b}}$ Chapman University, Argyros School of Business and Economics, One University Drive, Orange, CA, 92866, USA
}

\section{A R T I C L E I N F O}

\section{JEL classification:}

L62

F44

E32

Keywords:

Car registrations

Seasonality

Forecasting

Macroeconomic indicators

Socio-economic indicators

Vector autoregression

Granger causality

\begin{abstract}
A B S T R A C T
The automotive industry plays a key role in the European economy. In this paper, we determine which macro and socio-economic indicators have significant predictive power on car registrations - a proxy to automotive sector performance - across European countries. Contrary to the current literature which mainly focuses on long-term forecasting, we built our models on the highly seasonal monthly data of a medium-term period to make shortterm forecasts. Our approach utilises predictors identified by the literature review. Presented models are built on the Vector Autoregressive models and are accompanied by formal tests, such as the Granger causality test. We have found mixed evidence about the importance of selected predictors as no general patterns were identified. We have found that the most useful predictor is the total number of registrations from the strongest export partner and past registration figures in the analysed country. Car registrations are virtually inelastic to the change of public transportation costs, fuel prices and short-term interest rates offered to households in most of the analysed countries. We have received mixed results about household sentiment across countries. Countries with a higher level of GDP are more sensitive to the changes in unemployment.
\end{abstract}

\section{Introduction}

The automotive industry is an important industrial sector of almost all European economies. The highest proportion of the NACE C29.1 value (Manufacture of other transport equipment) to an overall NACE value reached in 2016, according to the Eurostat (2019) figures, is in the following countries: Slovakia (13.43\%), Hungary (11.28\%) and the Czech Republic (11.06\%). Germany is the country with the highest absolute value of automotive production. Its production value of 397,516 million euro in 2016 is 5.4 times higher than the second-largest producer, the United Kingdom. The proportion of the automotive sector to the overall economy ranked Germany in the fourth position among European Union countries with 7.03\% contribution. According to ACEA (2019), 13.3 million Europeans (6.1\% of all employed people) were working in the automotive industry in 2016. For many countries, high employment in the sector represents a systematic risk which requires detailed analysis and precautionary policies. The single market and international shareholding enable positive and negative economic spill over effects and therefore make monitoring and forecasting of the automotive sector relevant to less dependent economies. Various economic entities are interested in the performance of the automotive industry. Governments and central banks monitor the sector's stability and development as it directly affects national accounts and the stability of the economic system itself. Although a long-term analysis of the industry is one of the main interests, short term analysis can be used for the issuance of extraordinary policies, such as car scrappage programmes. Several European countries were able to introduce car scrappage programmes in 2009 as a response to the financial and economic crisis, which started only one year before (Cantos-Sánchez, Gutiérrez-i-Puigarnau, \& Mulalic, 2018). Stronger competitiveness in the automotive sector puts more pressure on production efficiency. This involves better utilisations of the production factors and short-term planning in general. Sa-Ngasoongsong, Bukkapatnam, Kim, Iyer, and Suresh (2012) identify the predictive horizon of 6-24 months as important for production planning due to the $12-60$ months of the concept-to-release time. An important group is financial investors who evaluate growth prospects and assess risks of the investment opportunities in the short window. Although households do not use sophisticated predictive models to gauge economic outlooks, short term predictions are inevitably considered when any large asset is being purchased. Buying a car is an

\footnotetext{
* Corresponding author.

E-mail addresses: homolka@utb.cz (L. Homolka), ngo@utb.cz (V.M. Ngo), pavelkova@utb.cz (D. Pavelková), tuan@utb.cz (B.T. Le), bdehning@chapman.edu (B. Dehning).
} 
important financial decision for both households and companies which involves cost-benefit thinking (Chng, White, Abraham, \& Skippon, 2019). It is a question to which extent short-term impulses affect purchasing behaviour.

The high complexity of the automotive sector requires a thorough analysis which goes further than a single time-series analysis. Current literature points to the various dimensions of the problem. It proposes different methodologies to tackle problems connected to the automotive sector performance or car sales/demand forecasting. One of them is the identification of factors influencing the passenger car demand, which spans over multiple disciplines from marketing, socioeconomics, macroeconomics, individual sector analysis, energy- and environmentrelated topics. However, these factors are often used as a separate set of factors. Moreover, studies usually connect those variables to a particular aspect of the car industry, such as environmental impacts of the transportation, preference of ultra-low emission vehicles based on the psychological factors or focus on the long-term analysis of technological and macroeconomic cycles. The interrelationship between factors or set of factors is not the core focus of the literature.

We add to this literature a new perspective: we provide short-term predictions which are based on the macro and socioeconomic factors observed in the medium-term window while carefully evaluating in-year seasonal effects. Estimated models reflect historical development and seasonality pattern in each country separately. Instead of forecasting car sales or total production of the automotive sector, we use the monthly data of new passenger car registrations to assess a dynamic of development in a one-year predictive window. The predictive part of our results might be used as an early warning system, while the variable analysis can help policymakers to focus on relevant dimensions when issuing a new policy.

The aim of the paper is to determine which macroeconomic and socioeconomic indicators have significant predictive power in the development of the automotive sector in the short-term horizon. We have set three research questions to outline our research framework, which would allow us to understand the dynamics of the car registrations in Europe.

RQ 1: Are there any short- and medium-term patterns across the car registrations in European countries?

By a short-term pattern, we understand seasonal fluctuations which occur within the period of one year. We define a medium-term as a common pattern over one wave of an economic cycle. Long term cycles typically span more than a decade and are not considered in our analysis.

RQ 2: Are there any universal economic variables which are significant predictors of car registrations? What are significant predictors in most of the analysed countries?

We expect that the significance and magnitude of macro and socioeconomic effects on the automotive industry will differ from country to country. However, many countries share a similar cultural, economic, and historical background. Therefore, common patterns should possibly appear and might be useful for forecasting.

RQ 3: How do the car registrations react to the changes in selected predictors in the short-term?

After statistically significant predictors are identified, the overall magnitude of the effect will be analysed. Selected Vector Autoregressive Model (VAR) allows us to measure and visualise the estimated effect of change of explanatory change on the dependent variable over time.

This paper is organized in the following way. Section 2 presents a literature review on passenger car forecasting. This part discusses economic factors and variables which are commonly used for forecasting in the automotive sector and reviews analytical methods and techniques which are being used in the literature. Data description and methodological settings follow in Section 3. Section 4 presents empirical results and provides a discussion. The conclusion summarises key findings and points to the paper's limitations and proposes future research directions.

\section{Theoretical background}

The first part of this section deals with the economic factors related to passenger cars purchases and passenger cars travel demand. The second part discusses the analytical methods used in the literature for both forecasting and inferential analysis.

\subsection{Economic factors}

The importance of other means of transportation is not considered in the literature review in detail. However, public transportation is considered as the main substitute of passenger car transportation and as such is contained in the forecasting model (proxied by the price of public transportation).

The car purchasing decision is driven by a set of factors which can be directly observable (e.g., disposable income) or have a latent nature (e. g., attitude towards environmental protection or psychological factors). Relevant factors can be identified in several ways, depending on the purpose of the research. If the purpose is theory testing, the domain of interest is well known as in the paper of Peters, Gutscher, \&amp; Scholz (2011). In this paper, important factors which explain purchasing behaviour with respect to car fuel consumption are identified based on the underlying theories, such as technology adoption model and diffusion theory (Peters, Gutscher, \& Scholz, 2011). Among other theories can be named the theory of planned behaviour or norm-activation theory (Bamberg, Fujii, Friman, \& Gärling, 2011). In other cases, when theory testing is not the main objective, then the research set of important factors can be elicited in the form of expert opinions or can be purely data-driven. This is a common approach to predictive analysis. We have opted for the literature review approach followed by a discussion with the practitioners to identify relevant variables. Unfortunately, we were not able to collect all relevant information (e.g., number of pending orders, short-term promotions, or true values of re-exports) due to the restricted availability of the data.

The nearest classification of the relevant factors to ours can be found in Fantazzini and Toktamysova (2015) who focus on the long-term prediction of the car sales in Germany. In their paper, factors are divided into three groups: technological aspects of the products, promotion and sales factors and Political, economic, and social environmental factors.

Table 1 summarises relevant factors which were used in the previous car demand and forecasting research.

The detailed literature review is restricted to only those factors which support our research questions and can be used for forecasting purposes. For this reason, the effects of extraordinary policies such as scrappage programmes or sales promotions are excluded in the review despite its importance. Discussion about important factors such as population size, age structure or type of residence (rural-urban) is omitted in the group of socio-economic factors as these factors are not updated on a monthly basis. We also omit discussion about psychological factors which are crucial to the entity-level analysis.

Macroeconomic factors shape and describe an economy in the broader scope than on the single household/company level. General economic development has historically been strongly associated with an increase in the demand for transportation and particularly in the number of car and vehicle ownership (Dargay \& Gately, 1999). Surprisingly, very little research has been done on the determinants of vehicle ownership across the countries with different levels of income (a proxy for the economic development of the country). Perhaps the most famous approach to understanding the relationship was developed by Dargay and Gately 
Table 1

Identified factors affecting car registrations and sales based on the literature review. Values in the brackets show indicators used in the forecasting models.

\begin{tabular}{|c|c|}
\hline Identified Factors & Source \\
\hline $\begin{array}{l}\text { Macroeconomic factors } \\
\text { (Unemployment rate) }\end{array}$ & $\begin{array}{l}\text { Tanner (1975); Dargay and Gately (1999); } \\
\text { Dargay, Gately, and Sommer (2007); Dargay } \\
\text { (2007); Haugh, Mourougane, and Chatal } \\
\text { (2010); Nolan (2010); Kloess and Müller } \\
\text { (2011); Prieto and Caemmerer (2013); } \\
\text { Fantazzini and Toktamysova (2015); } \\
\text { Konstantakis, Milioti, and Michaelides (2017); } \\
\text { Curl, Clark, and Kearns (2018); Pavelková } \\
\text { et al. (2018) }\end{array}$ \\
\hline $\begin{array}{l}\text { Travel Demand Management } \\
\text { (Public transportation costs) }\end{array}$ & $\begin{array}{l}\text { Cervero and Kockelman (1997); Ewing and } \\
\text { Cervero (2001); Gärling (2002);Loukopoulos, } \\
\text { Jakobsson et al. (2004); Gärling and } \\
\text { Schuitema (2007); de Palma and Kilani } \\
\text { (2008); Ryan, Ferreira, and Convery,(2009); } \\
\text { Chen et al.,(2010); Eriksson et al. (2010); } \\
\text { Redman, Friman, Gärling, and Hartig (2013); } \\
\text { Brand, Anable, and Tran (2013) }\end{array}$ \\
\hline $\begin{array}{l}\text { Socio-economic factors (Economic } \\
\text { Sentiment) }\end{array}$ & $\begin{array}{l}\text { Garner (1991); Bram and Ludvigson (1998); } \\
\text { Easaw, Garratt, and Heravi (2005); Buehler } \\
\text { (2011); Metz (2012); Dees and Brinca (2013); } \\
\text { Ritter and Vance (2013);Copeland (2014); Van } \\
\text { Wee (2015) Hjorthol (2016); Klein and Smart } \\
\text { (2017); }\end{array}$ \\
\hline $\begin{array}{l}\text { Financial conditions (short term } \\
\text { interest rate) }\end{array}$ & $\begin{array}{l}\text { Prieto and Caemmerer (2013); Lee and Cho } \\
\text { (2009); Haugh et al. (2010); Alper \& Mumcu } \\
\text { (2007);Khoury (2015);Muhammad, Hussin, } \\
\text { Razak, Rambeli, and Tha (2013) }\end{array}$ \\
\hline $\begin{array}{l}\text { Fuel and energy prices (gas station } \\
\text { fuel price) }\end{array}$ & $\begin{array}{l}\text { Alper \& Mumcu (2007); Haugh et al. (2010); } \\
\text { Kloess and Müller (2011); Khoury (2015); } \\
\text { Grigolon, Leheyda, \& Verboven, 2016; } \\
\text { Alberini \& Bareit, } 2019\end{array}$ \\
\hline
\end{tabular}

(1999). In the consequent analysis, Dargay et al. (2007) authors estimated models based on the panel data of 45 countries that include 75 percent of the world's population. Their analysis is based on the long-term time-series covering the period from 1960 to 2002. Results suggest that there is a non-linear relationship between vehicle ownership and a level of income in most of the countries except for Luxembourg, Iceland, Ecuador, and Syria. More specifically, vehicle ownership rises at a slow pace at the lowest levels of per-capita income countries, then about twice as much as income growth at middle-income levels (from $\$ 3,000$ to $\$ 10,000$ per capita). Real income was showed to be a crucial determinant in the forecast of automobile sales (Dargay, 2007; Haugh et al., 2010; Pavelková et al., 2018; Tanner, 1975). Nolan (2010) has conducted a longitudinal analysis of the Irish household sample and found that the income and the previous car ownership are the two most important factors of car ownership. Nolan found that the long-run effect of the permanent income has a stronger effect than a short-run (current) financial situation of the household. Finally, at the high-income level countries, car ownership rate grows proportionally to income growth but is restricted by the level of saturation. This situation happened in Austria where car ownership level has already reached the saturation level in 2010, and therefore, the income elasticity is even decreasing (Kloess \& Müller, 2011). Other characteristics, such as household size, number of kids, or number of regular commuters should be used instead of the household income for understanding car sales. Fantazzini and Toktamysova (2015) built a multivariate forecasting model on the level of car manufacturer which has involved (among others) Gross Domestic Product (GDP) and unemployment variables. They found that the inclusion of theses variables improves predictive ability on the time horizon up to 2 years. Konstantakis et al. (2017) found that unemployment rate negatively Granger-caused new car sales on the lag of 2 months in Greece while other factors as fuel prices, GDP and Economic sentiment do not. Curl et al. (2018) have analysed car ownership in the context of distress households in deprived urban communities. Contradictory to the results of Konstantakis et al. (2017) they found that during the period 2006-2008 unemployed target group was more likely to acquire a car than the employed group. Authors provided a possible explanation that car availability enables unemployed people to reach working opportunities located in a further distance from their homes. It was also found that unemployment does not have a consistent significant impact on new car segment choice compared to small used segment choice. Overall, unemployment is more like to have a positive impact on choosing used cars while having negative impacts on the new cars purchasing decision (Prieto \& Caemmerer, 2013).

Travel demand management (TDM) is a set of policies and measures designed to mitigate increasing environmental and societal costs from car usage (Brand, Anable, \& Tran, 2013; Eriksson, Nordlund, \& Garvill, 2010; Gärling et al., 2002; Loukopoulos, Jakobsson, Gärling, Schneider, \& Fujii, 2004). Such policies aim to change (lower) demand for car ownership and use by various means (de Palma \& Kilani, 2008; Ryan, Ferreira, \& Convery, 2009). TDM can be divided into hard and soft types. Hard type TDM aims at infrastructure development, rationalisation of the public transportation services and other measures which does not directly influence car owners and users to voluntarily change the mode of transport. Authors Cervero and Kockelman (1997) and Ewing and Cervero (2001) found that with increasing density of the urban area, more diversified usages of land, and with designed pedestrian-oriented can reduce the car-use and increasing the non-auto travels using public transports system and other means. Gärling and Schuitema (2007) found that the increasing cost for car use or prohibiting car use may be necessary regarding the insignificant effects of soft TDM measures. However, hard TDM measures should be combined tightly with measures providing attractive travel alternatives such as reducing fares and increasing the quality of public transports (Chen, Esteban, \& Shum, 2010; Gärling \& Schuitema, 2007). Redman et al. (2013) summarise effects of qualitative attributes of public transportation on car usage. They conclude that the change in transportation services is an important factor, especially in the short term. Other physical quality factors (e.g., reliability, speed, accessibility) and perceived factors (e.g., comfort, safety, convenience) determine the duration of the modal split.

Socio-economic factors are a broad group of factors and indicators. The second significant move in sociodemographic trends is about the less car-oriented among young people in developed economies (Hjorthol, 2016; Ritter \& Vance, 2013). Klein and Smart (2017) found that young adult in America today own fewer cars than the previous generation. However, the main reasons in America for this observation is about the financial insufficient of most of the young adult leading to the delayed of car purchasing(Copeland, 2014). In Germany, the UK, and Norway, the same pattern was found that young people tend to live in highly dense urban areas and are less car-oriented. In these Europe countries, the main reason is about the emerged new lifestyle of young people such as spending longer on education, delaying establishing a family or voluntary childless (Buehler, 2011; Hjorthol, 2016; Metz, 2012; Van Wee, 2015). Uncertainty of future prospects is another important factor which can be measured indirectly. Consumer confidence indexes are usually based on the monthly survey of customers about their expectations in the near terms. For forecasting purpose, consumer confidence is assumed to account for the psychological channels which influence the purchasing decisions other than just income and prices (Garner, 1991). One of the most leading indicators for the expected financial conditions and prosperity expectations of a customer, in general, is the Empirical studies have shown that in general, the consumer confidence index is good predictors for future consumptions, especially the durable goods. Bram and Ludvigson (1998) suggested that adding the consumer confidence index explained $9 \%$ more on the variations of growth of household expenditures in the next period. Especially, the consumer confidence index helped to explain the motor vehicle spending 5\% more accurate with statistical significance (Bram \& Ludvigson, 1998). Other researchers found that the forecasting 
powers of consumer confidence index are already included in other macroeconomic variables under normal conditions, but it showed a significant increase in forecasting powers when it features large changes during the crisis, for instance (Dees \& Brinca, 2013). This can be explained by the mechanism that consumer confidence is good leading indicators for labour income and then, in turn with higher expected income, people are more willing to consume (Easaw et al., 2005).

Therefore, higher consumer confidence index can indicate the higher travel demand and a good incentive for a car purchase. The Total Confidence Indicator which is used in our paper is provided by the European Commission. The Total Confidence Indicator assesses the subjective evaluation of the financial situation, unemployment, and level of savings in the next 12 months.

Another factor which has an impact on both micro and macro level is the financial conditions of the households and companies. At the microlevel, the option for purchasing a new car with credit or purchasing a new car with cash can have an impact on purchasing behaviour (Prieto \& Caemmerer, 2013). They found those consumers with available credit usually use it to purchase larger and more expensive car categories. Indeed, the elasticity of the credit variable on new small segment market share is particularly important. Financing a car purchase by credit increases the decision to buy a small new car from 17 to 30.9 percent. At the same time, financing a purchase by credit significantly decreases the choice of small used cars from 26.9 percent to 10.9 percent (Prieto \& Caemmerer, 2013). In the macro level, the availability of consumer credits and easy access to them may increase demand for durable goods by reallocating income overtime (Haugh et al., 2010; Alper \& Mumcu, 2007; Khoury, 2015). Different types of measures are used to investigate the impacts of financial condition on car demand. Using a simple model of car sales growth for explaining the fall in car sales in the last quarter of 2008 in OECD countries and some other countries, it is found that a significant effect of financial conditions was found in all G7 countries, except France. In the United Kingdom and Japan, tight financial conditions are estimated to influence sales only with a lag. Estimations indicate that tight credit conditions could explain more than $80 \%$ of the collapse in car sales at the end of 2008 in the United States and Canada (Haugh et al., 2010). Interest rates closely relate to inflation. The difference between the two (real interest rate) is frequently used as a macroeconomic variable. Result of (Muhammad et al., 2013) suggests that inflation and monetary policy rate, a proxy for interest rate, did not have direct impacts on car sales. Instead, they have significant impacts on income variables, which in turn, significant impacts the car demands.

Passenger car remains highly dependent on oil as the based fuels (Kloess \& Müller, 2011). Therefore, the price of energy, specifically oil price, directly affects the cost of transportation by passenger car (Lee and Cho, 2009). Therefore, it is usually included as the control factors in studies about forecasting car demand or study the change in car demand on the changes of other factors (Alberini \& Bareit, 2019; Haugh et al., 2010; Alper \& Mumcu, 2007; Khoury, 2015; Kloess \& Müller, 2011; Grigolon, Leheyda, \& Verboven, 2016). In all the studies reviewed which have energy price as the control variables, it did have significant impacts on the car demand. Generally, an increase in the price of oil has negative impacts on the demand for passenger cars (Haugh et al., 2010; Khoury, 2015). Moreover, there is the trend of increasing prices level of automotive fuels, which is rooted in the increasing demand for oil and policy interventions to reduce CO2 emissionsHaugh et al., 2010). This might lead to the acceleration of the demand for smaller, more fuel-efficient cars when consumers make a car purchasing decision.

\subsection{Overview of empirical models and analytical methods}

The econometrical foundation of the car demand modelling can be traced back to Tanner (1975) who described the relationship between income and car ownership by an S-shaped logistic curve. Train, K. (1993) provided a framework for econometric models of choice on the level of individuals. De Jong, Fox, Daly, Pieters, \& Smit, (2004 p. 379) have compared several models which have emerged in the literature on the following criteria: "inclusion of demand and supply side of the car market, level of aggregation, dynamic or static model, long-run or short-run forecasts, theoretical background, inclusion of car use, data requirements, treatment of business cars, car type segmentation, inclusion of income, of fixed and/or variable car cost, of car quality aspects, of licence holding, of socio-demographic variables and of attitudinal variables, and treatment of scrappage". Anowar, Eluru, Miranda-Moreno, \& Lee-Gosselin, (2015) extends the summary with the notion of endogeneity/exogeneity and dynamic/static nature of the problem. Authors provide a decision matrix of methods based on the combination of abovementioned characteristics and a type of vehicle demand modelling purpose (e.g., vehicle count, vehicle ownership duration, vehicle transaction). They propose models of generalised ordered and multinomial logit, duration model with single and competing hazards or simultaneous equation models. Brathwaite \& Walker (2018) state that car demand modelling is predominantly about forecasting rather than causal inferential analysis. Quality of the forecasting performance was also an object of previous studies. Pierdzioch, Rülke, and Stadtmann (2011) analysed forecasts of car sales in the U.S. and forecasts of car registrations in Japan in terms of three concepts bias and rationality of forecasts and (anti-)herding behaviour of forecasters. Authors found that forecasts are neither unbiased (predictions systematically over/underestimate reality) nor rational (there is a non-negative correlation between errors and known information at the time of forecast) and that forecasters adjust their predictions according to their peers.

Following the work of Tanner (1975), Dargay and Gately (1999) suggest the Gompertz function as an alternative to logistic the S-shaped curve of the income for the development of car ownership. Accordingly, car ownership rises slowly in the beginning phase, then increases steeply, and approaches a saturation level at the end. Dargay and Gately (1999) state that the Gompertz model is more flexible than the logistic model due to allowing different curvatures from low to high-income levels. Using the Gompertz model, they estimate the saturation level and the long-run equilibrium level of vehicle ownership for a full range of countries, 25 countries from the lowest to most upper income, over the period 1960-1992. Dargay et al. (2007) expand the estimates for 45 countries, including $75 \%$ of the world population, by pooled data from 1960 to 2002. Bouachera \& Mazraati, (2007) find that the logistic model tends to overestimate car ownership, and the forecast results of the Gompertz model appears to be less reliable than the ones of the quasi-logistic model. Huo and Wang (2012) also confirm that the Gompertz curve fits the Chinese data than the logistic curve. Although Ingram and Liu (1999) question its validity as observing an increase in the saturation levels over time, the accepted validity of the Gompertz model makes itself common to manifest the long-term relationship between vehicle ownership and the income. Haugh et al. (2010) employ the Gompertz model together with the framework of Greenspan \& Cohen (1999) to estimate trend car sales for OECD countries in the period 1995 to 2020. The Gompertz curve model of Dargay and Gately (1999) is estimated under the assumption that all countries have the same saturation level. Dargay et al. (2007) relax this restriction by adding population density and urbanization to the model, which results in different saturation levels for different countries. Pavelková et al. (2018) validated the usefulness of the Dargay's model on the 38 the automotive markets accounting for more than $80 \%$ of the world passenger cars in use.

A novel methodology which allows better operationalisation of a large number of economic variables to improve predictive accuracy in the context of automotive sales was developed by Wang, Chang, and Tzeng (2011). The methodology consists of two steps. First, the stepwise regression is employed to choose the most influential economic inputs. Next, selected variables are used in the adaptive-network-based fuzzy inference system (ANFIS) to make a forecast. Empirical results show that the ANFIS models outperform the two competing forecast models: 
artificial neural network (ANN) and autoregressive integrated moving average model (ARIMA). Another example of the improvement by incorporating other variables on projecting vehicle sales is the FEEI model proposed by Huo and Wang (2012). Authors simulate private car ownership in China based on the income levels, incorporate car purchase prices, examine the influence of different scrappage patterns, and divide sales into purchases for replacements and fleet growth. As a result, the FEEI model not only outperforms previous models but also enable simulating various policy scenarios.

Sa-Ngasoongsong et al. (2012, p. 875) have used a "structural relationship identification methodology, a combination of Granger-causality, statistical unit root, cointegration tests, and weakly exogeneity, to identify the dynamic couplings among economic indicators and automotive sales." This methodology limits the disadvantage standard approaches which cannot handle nonlinear relations between variables and nonstationary times series of underlying time series. Fantazzini and Toktamysova (2015) propose an application of variants of multivariate autoregressive models to forecast car sales. Their results show that these models offer statistical advantages over the competing models. Konstantakis et al. (2017) used a VAR approach in connection with the Granger causality test and generalised impulse response functions.

Based on the literature review, the Vector Autoregressive Modelling strategy is adopted in this paper for fulling the research objectives. According to Garrat et al. (2012), the VAR approach does not require the identification of long-term relations because all information is gained from the observed observations. No economic theory which would impose restrictions or would suggest optimal lag relevance was used in the paper. Therefore, we have decided not to use a Structured Vector Autoregressive model. In the light of Brathwaite \& Walker (2018) criticism of an absence of causal analysis, we add an analysis Impulse response functions and Granger Causality tests (although it's not causality in a strict sense which is possible to identify in experimental design settings).

\section{Data and methods}

This paper aims to identify factors with predictive power. The focus on the short-term forecasting limits the availability of the data. The forecasting horizon is set to 12 consecutive months. Therefore, data with monthly release frequency are required for the analysis. Unfortunately, some important socio-economic data must have been excluded. Perhaps the most important macroeconomic indicator, GDP, is released quarterly. Sociodemographic figures, such as the composition of education, age structure and others are available on an annual basis.

Variables with a longer frequency of release cannot be converted into higher frequency easily. If the quarter GDP is split to thirds to estimate monthly GDP, then the estimation of the model would not be correct due to the artificial autocorrelation. As Ghysels \& Marcellino (2018) show, inferential test such as Granger Causality tests would not be valid. Although several methods for data imputations in the context of mixed-frequency time series were introduced (Schorfheide \& Song, 2015), we have decided to use directly observable proxies instead.

Table 1 summarised important factors and corresponding literature. Table 2 contains the indicators and origin of the data for each of the identified factors. Macroeconomic factors are represented by two variables. The monthly growth rate of unemployment is an indicator which is closely followed by experts and the public. Effect of unemployment is partially contained in the Total Confidence Indicator used in the group of Socio-economic factors. This can cause a problem of multicollinearity, which results in higher estimates of standard errors and therefore estimates are likely to be not statistically significant. Past values of the passenger car registrations can be considered as another variable due to the autoregressive nature of the forecasting model. OECD (2010) have pointed to the correlation between car sales and the total output of the economy through the private consumption channel. We therefore use
Table 2

List of selected factors and indicators with a possible effect on car sales and registrations.

\begin{tabular}{llll}
\hline Factor & Indicator & Variable Name & Source \\
\hline $\begin{array}{c}\text { Macroeconomic } \\
\text { factors }\end{array}$ & $\begin{array}{l}\text { Unemployment } \\
\text { Car registrations in } \\
\text { the Economy to } \\
\text { which the analysed } \\
\text { country has the }\end{array}$ & $\begin{array}{l}\text { Unemployment } \\
\text { Registration 2 }\end{array}$ & $\begin{array}{l}\text { Eurostat } \\
\text { European } \\
\text { Automobile }\end{array}$ \\
& biggest exports & & $\begin{array}{l}\text { Manufacturers } \\
\text { Association }\end{array}$ \\
Travel Demand & $\begin{array}{l}\text { Public transportation } \\
\text { Management }\end{array}$ & Inflation & Eurostat \\
Socio-economic & $\begin{array}{l}\text { Total Confidence } \\
\text { factors }\end{array}$ & Sentiment & European \\
& $\begin{array}{l}\text { Indicator (Major } \\
\text { purchases over the }\end{array}$ & & Commission \\
Financial & next 12 months) & & \\
conditions & $\begin{array}{l}\text { Short term interest } \\
\text { rates for households }\end{array}$ & ST & European Central \\
Fuel and energy & Fuel price at the gas & Fuel & Bank \\
prices & station & & European \\
Ear registrations & Total number of & Registration & Agency \\
(forecasted & registered personal & & European \\
value) & cars & & Manufacturers \\
& & & Association \\
\hline
\end{tabular}

car registration (which differs slightly from car sales) as an alternative proxy for a current and past performance of the economy. Due to the openness of the European economies, we add a new variable to our analysis that was not used before. For each country we have identified the strongest export partner, and car registrations of the partner's country entered the analysis. This addition was motivated by a discussion with experts in the Central Europe region who pointed to the strong connections to the German automotive sector. Moreover, this variable can also contain some information about unreported values of re-exports. Indicator Public transport costs were selected for the factor Travel Demand Management. Other variables for the soft or hard types were not available. Variables which measure the change of modal split, use of car sharing or environmental incentives are not reported on the requested frequency. The Total Confidence Indicator (TCI) measures a general economic sentiment of the population. TCI was developed by the European Commission and allows comparability of results across all European Union countries. This indicator reflects dimensions of perceived financial and economic situation, unemployment and savings outlook over the period of 12 months. Contrary to the unemployment level in the macroeconomic factor, this indicator is forward-looking. We have not used other indices, such as the Purchasing Manager Index or the ZEW index (for Germany) or as we have found high correlation during the development of the paper. Current and past financial condition available for households is proxied by the short-term interest rates. The outlook of the financing is contained in the TCI. Factor Fuels and Energies is measured by the prices of Euro-super 95 per litre at the gas stations, which were computed as an average of the weekly values.

Data were collected for 21 countries in the European Union (if the data is not available from all sources, the EU country is dropped from the analysis). The analysed period starts in January 2010 and ends in December 2017. A time period from 2010 to 2016 was used as a training period for building the country-specific predictive model. Predictive performance was assessed in the test period of the year 2017.

Seasonal Decomposition of Time Series by Loess (STL) model (Cleveland, Cleveland, McRae, \& Terpenning, 1990) was employed to answer the first research question "Are there any short- and medium-term patterns across the car registrations in European countries?". This approach allows decomposition of the underlying time series into the long-term components, trend and cycle, and to a short-term seasonal component. The seasonal component contains effects with a duration of less than one year, which regularly appear over a longer period. We have used an option to identify constant seasonality model, 
which assumes that the seasonal effects are not linked to the trend component of the time series. A set of seasonal effects which can be inspected visually is the outcome of this analysis. Also, we have employed a Multiple Seasonal Decomposition approach by Hyndman at al. (2018) to assess the strength of the seasonality. The proposed index ranges from 0 - no seasonality, 1- seasonality dominates the trend.

The second research question about important variables is answered in two steps. In the first one, we used the partial Granger Causality test to test Granger causal relationships ( $g$-causality) between the variables. We used both conditional and partial Granger Causality test, which are used predominantly in the neuroscience. Partial Granger test allows full elimination of additional variables and latent variable which have confounding effects (Guo, Seth, Kendrick, Zhou, \& Feng, 2008). The analysis was limited to "variable $\rightarrow$ registrations" direction of the relationship, although it's possible to test the opposite direction as well. The idea behind the Granger causality is that cause cannot be observed before the studied effect. Before the Granger Test is performed, data were made stationary by differencing (no time series was trend stationary). Analysis of conditional Granger test was added for completeness. It is well established that the Granger Causality test is very sensitive to the selected lag (Gujarati, 2009). The optimal lag size was determined by the Akaike information criterion (AIC). Therefore, our results are one of the potentially correct solutions as the lag selection is subjective to some extent (e.g., other criteria than AIC are available). The second step is tabulating statistically significant variables of the estimated models.

Fitting of the VAR models a stationarity testing was done in the statistical software R 3.5.3. Library vars and urca by Pfaff (2008) were used. All VAR models were fitted, and irf analysis was performed on stationary data. The Augmented Dickey-Fuller test (ADF test) was used to determine whether the analysed time series contain a unit root and if so, how many differences are required to achieve stationarity. The ADF test requires setting a number of lags in advance. We have run two analyses to determine the correct number. Firstly, a set of models with different lag size were fit, and the model with the lowest value of Akaike information criterion (AIC) on the training sample was selected. This approach identified one lag as the best settings for most of the models. Secondly, we have followed the recommendation by Schwert (1989) as in formula (1) for setting a maximal length in eq. (1)

$p_{\max }=$ integer $\left[12\left(\frac{T}{100}\right)^{1 / 4}\right]=11$.

Time series were recorded on 96 observations. Therefore, the recommended number of lags to consider is 11 . Then, the maximum number of recommended differences was made.

Optimal lag size for the VAR model was identified by minimising the AIC value. The seasonal VAR models with 11 dummy variables were built on the training period from 2010 to 2016. We have adopted a standard OLS approach to estimate the VAR as described in Pfaff (2008). All point predictions are accompanied with the confidence intervals on the $90 \%$ confidence level. Forecasting performance of models was assessed in three ways. First, two common fit indices: Mean Square Error (MSE) and Mean Percentage Error (MAPE) were computed. Secondly, we report the number of months-forecasts for which our predictions were outside of this confidence interval. Third, we visualise our predictive uncertainty in the form of fancharts computed according to the approach by Britton, Fisher, and Whitley (1998, pp. 30-37).

To address the third research question, we used the cumulative orthogonalized impulse response function (irf). Irf allowed us to visualise the immediate effects of the controlled shock on the time series in the upcoming 12 months. To assess the uncertainty of the estimated effects, bootstrapped $80 \%$ confidence intervals computed on 100 replications were added. Orthogonalized irf were selected as we have expected that the change of one variable simultaneously affects other variables in the system. Due to limited space, we limit visual results of impulse response functions (irf) for countries which were identified in the introduction of the paper. The Czech Republic was selected due to its strong dependency on the automotive sector and a close connection to the strongest European economy - Germany. Slovakia was selected as a country with the strongest automotive sector measured by GDP per capita from all European countries. Germany is the strongest economy in Europe and is also the biggest car manufacturer. Ireland was selected as a smaller economy with a strong neighbour - the UK, but without its own strong automotive sector.

\section{Results and discussion}

The empirical evidence is evaluated to answer the three research questions in this section. The first research question aims to identify shared patterns across European countries. In the first step, we visually inspect the time series to identify strong trend patterns. Time series are decomposed and seasonal patterns are identified. Original values in levels can be seen in Fig. 1. Analysed countries can be divided into three main groups. The first group contains countries with a non-negative growth rate throughout the analysed period. The second group is characterised by the U-shape development of car registrations. Such countries are typically having higher GDP per capita compared to the countries with fast growth. The last group of countries does not share a similar pattern of development. In the Greece case, we see plummeting of car registrations in the period before 2011. After this period Greece found itself in a stable place around 7000 new cars per month. Countries such as Netherlands, Luxembourg or the UK fluctuated around their respective mean values. It can be concluded that there is no shared pattern of growth across analysed countries. We can see a strong seasonality in almost all countries.

Closer inspection of the seasonality pattern allows us to specify the forecasting model better. As described in the Methods section the STL model with a constant seasonality trend was employed. Isolated seasonal effects which repeat every year can be found in Fig. 2. Two types of patterns have emerged. The first one has declining car registrations towards the end of the year, whereas the second one usually growth from its minima, which happens in the 8th or 9th month.

The strength of the seasonal component relative to the remaining parts (trend and residuals) of the model is computed in the next step. A country with the lowest seasonality effects is Latvia $(0.41)$. The highest place occupies the UK with the values of seasonal strength 0.97 . Predictive benefits come from a better understanding of the medium-period trend, which diminishes as the seasonality index increases.

From the selected countries, Slovakia is influenced by seasonal effects the least (0.59), Slovakia is followed by the Czech Republic (0.71). Ireland has a stronger seasonal pattern $(0.81)$ but no visible trend as can be seen from Fig. 1. Germany records the second-highest seasonal pattern (0.91) just under the United Kingdom (0.97).

Before we proceed with evaluating empirical evidence by VAR and Granger test, time series need to be transformed to be stationary. Table 3 presents the recommended number of differences to achieve stochastic stationarity. KPSS test was computed to verify the findings of ADF.

Based on the values in Table 3, data were transformed before any model was created. Table 4 presents achieved p-values of tests across countries and variables. Low values indicate that there is a Granger causal relationship from the variable (indicators from tab 2) on car registrations while removing the effect of all other variables in the model. F.

If the conditional Granger test is statistically significant and partial is not (e.g., unemployment in Finland), then an analyst will benefit from including the variable to the model if there is some other variable which supplements the original variable. Which variable is the supplementing one can be found in ad-hoc analysis on restricted models. Variable Unemployment (current level) was identified as the most frequent determinant of car registrations. Car registrations in the strongest export country seems to be important only for a few countries. However, the 

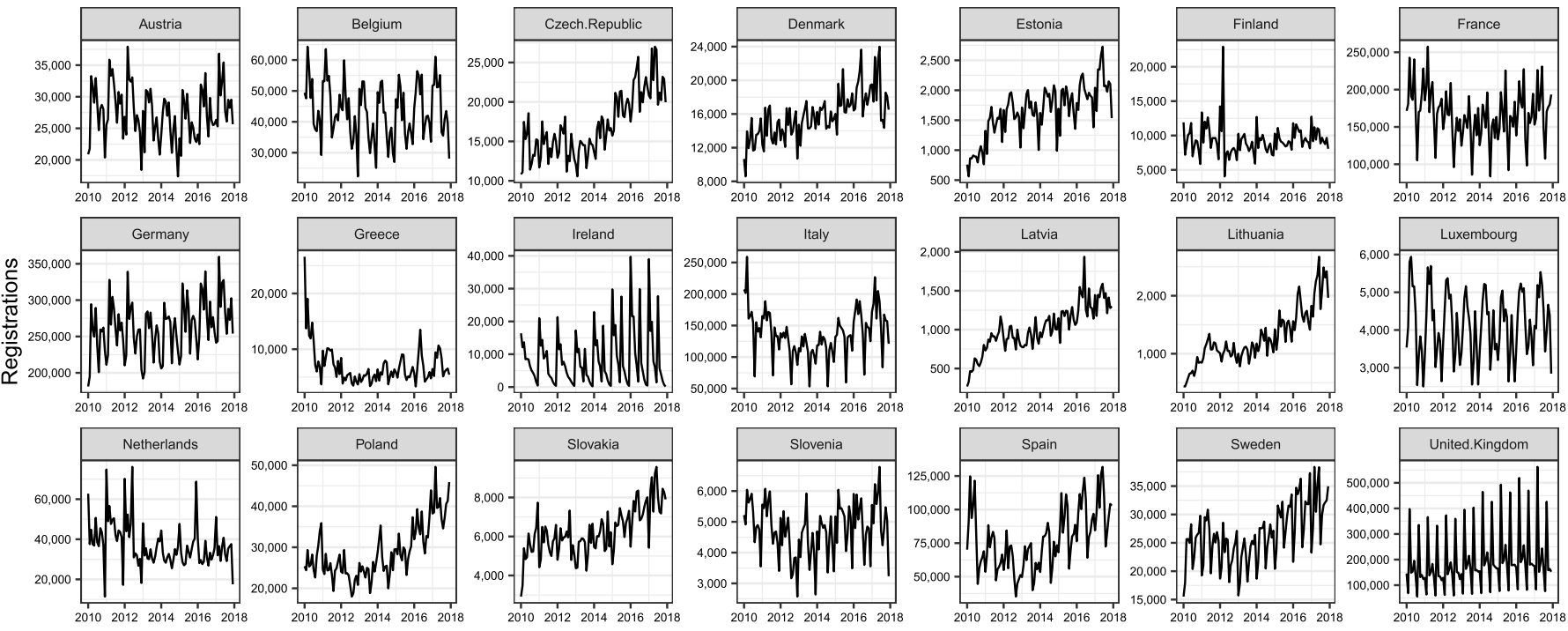

Fig. 1. Time series of car registrations in levels. There was no common trend across European countries.
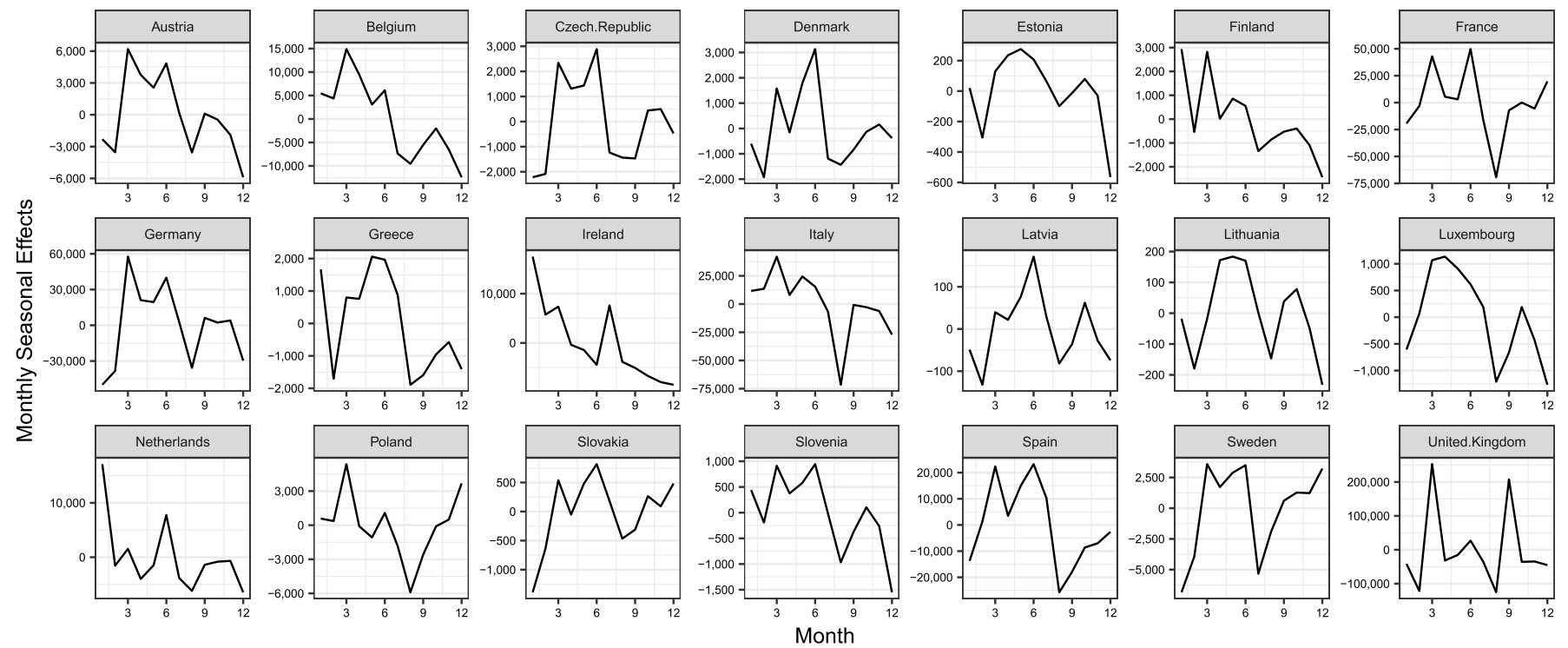

Fig. 2. Constant seasonality pattern identified by the STL approach.

Czech Republic is among the countries as expected. Cost of public transport (inflation) cannot be considered as a general factor directly influencing car registrations as only 5 of 21 countries have shown some connection. Interestingly, the impulse response function later provides different results for Slovakia and Germany. Household sentiment does not partially Granger cause car registrations. However, the predictive system can benefit from its inclusion as the conditional causality was identified in some countries. Access to finances through the short-term interest rates was not identified as a determining factor. Fuel prices are considered as an important predictor only in Austria.

In the next stage, we identify a multivariate VAR model for each country and analyse statistically significant coefficient from the VAR equation corresponding to car registrations.

No statistically significant predictors were found in the countries Finland, Ireland and Luxembourg. For these countries, only seasonal dummy variables were found statistically significant. Some factors turned out to be statistically non-significant. This can be explained by multicollinearity of predictors (e.g., the current level of unemployment and household sentiment). Regression models then have difficulties in estimation correct value of standard error, which yields into statistically non-significant estimates. This is common in forecasting models where the model is judged by its predictive ability rather than explanatory power. Impulse response function discussed later provides more explanatory information.

Past values of registrations were identified as the most frequent predictor across analysed countries. Results from Table 5 only partially support results from the Granger Tests. Unemployment rate and car registrations in the export country were the most frequent among other variables. Similarly to the Granger causality tests, no pattern has of statistically significant predictors emerged from the VAR analysis. The two approaches have not identified predictors that can be used universally as asked in the second research question. Both results call for the need of individual forecasting models with variable selection appropriate to the particular country.

Identified VAR models had very good predictive performance as can be seen from Fig. 3. This visualisation is another form of verification, whether selected predictors are well chosen or not. It cannot directly say, as opposed to the formal statistical test above, what is the contribution of each predictor.

Table 6 summarises the performance by selected indicators: square 
Table 3

A number of differences to be made to achieve stationarity. Results show a number of differences according to ADF - KPSS test.

\begin{tabular}{|c|c|c|c|c|c|c|}
\hline Country & Fuel & Inflation & Registrations & Sentiment & Short-Term & Unemployment \\
\hline Austria & $1-1$ & $1-2$ & $0-1$ & $1-1$ & $1-2$ & $1-1$ \\
\hline Belgium & $1-1$ & $2-2$ & $0-0$ & $1-1$ & $1-2$ & $1-1$ \\
\hline Czech Republic & $1-1$ & $1-1$ & $1-1$ & $1-1$ & $1-1$ & $1-1$ \\
\hline Denmark & $1-1$ & $1-2$ & $0-0$ & $1-1$ & $1-1$ & $1-1$ \\
\hline Estonia & $1-1$ & $0-2$ & $0-1$ & $0-0$ & $1-1$ & $0-1$ \\
\hline Finland & $1-1$ & $0-2$ & $0-0$ & $1-1$ & $1-2$ & $0-0$ \\
\hline France & $1-1$ & $1-1$ & $0-1$ & $1-1$ & $1-2$ & $0-1$ \\
\hline Germany & $1-1$ & $1-1$ & $0-0$ & $0-0$ & $1-2$ & $1-1$ \\
\hline Greece & $0-2$ & $0-1$ & $0-1$ & $1-1$ & $1-2$ & $1-1$ \\
\hline Ireland & $1-1$ & $2-1$ & $0-0$ & $1-1$ & $1-2$ & $1-1$ \\
\hline Italy & $1-1$ & $2-1$ & $0-1$ & $1-1$ & $1-2$ & $1-1$ \\
\hline Latvia & $1-1$ & $2-2$ & $1-0$ & $0-1$ & $1-2$ & $1-1$ \\
\hline Lithuania & $1-1$ & $0-1$ & $1-1$ & $0-1$ & $1-1$ & $1-1$ \\
\hline Luxembourg & $1-1$ & $1-2$ & $0-0$ & $1-1$ & $1-2$ & $1-1$ \\
\hline Netherlands & $1-1$ & $2-2$ & $0-0$ & $1-1$ & $1-2$ & $1-1$ \\
\hline Poland & $1-1$ & $0-2$ & $1-1$ & $1-1$ & $1-2$ & $1-1$ \\
\hline Slovakia & $1-1$ & $2-2$ & $0-1$ & $1-1$ & $1-2$ & $1-1$ \\
\hline Slovenia & $1-1$ & $2-2$ & $0-1$ & $1-1$ & $1-2$ & $1-1$ \\
\hline Spain & $1-1$ & $0-2$ & $0-1$ & $1-1$ & $1-2$ & $1-1$ \\
\hline Sweden & $1-1$ & $0-3$ & $0-1$ & $1-1$ & $1-2$ & $1-0$ \\
\hline United Kingdom & $1-1$ & $0-1$ & $0-0$ & $1-2$ & $1-1$ & $1-1$ \\
\hline
\end{tabular}

Table 4

List of p-values of the Partial Granger Causality tests. Lag used in the test was selected by the best performing model with respect to the MSE criteria.

\begin{tabular}{|c|c|c|c|c|c|c|}
\hline Country & Unemployment & Registrations2 & Inflation & Sentiment & Short-Term & Fuel \\
\hline Austria & 0.38 & 0.16 & 0.66 & 0.20 & 0.45 & $0.039 * *$ \\
\hline Belgium & 0.21 & $0.001 * * *$ & 0.77 & 0.93 & 0.69 & 0.18 \\
\hline Czechia & 0.69 & $0.004^{* * *}$ & 0.84 & 0.25 & 0.69 & 0.77 \\
\hline Denmark & 0.67 & $0.059^{*}$ & 0.96 & $0.006 * * *$ & 0.89 & 0.30 \\
\hline Estonia & $0.01^{* * *}$ & 0.97 & 0.71 & 0.24 & 0.11 & 0.11 \\
\hline Finland & 0.34 & $0.075^{*}$ & $0.097^{*}$ & 0.81 & 0.82 & 0.16 \\
\hline France & 0.46 & 0.21 & $0.094 *$ & 0.64 & 0.37 & 0.61 \\
\hline Germany & 0.35 & 0.43 & 0.39 & 0.90 & 0.36 & 0.76 \\
\hline Greece & 0.37 & 0.13 & 0.71 & $0.02^{* *}$ & $0.062^{*}$ & 0.89 \\
\hline Italy & 0.53 & 0.34 & 0.45 & 0.45 & 0.46 & 0.98 \\
\hline Ireland & $0.001 * * *$ & 0.51 & 0.79 & 0.61 & 0.41 & 0.25 \\
\hline Latvia & 0.61 & 0.45 & 0.29 & 0.81 & 0.83 & 0.64 \\
\hline Lithuania & 0.58 & 0.31 & 0.60 & 0.54 & 0.81 & 0.27 \\
\hline Luxembourg & $0.069^{*}$ & 0.86 & 0.91 & 0.78 & 0.71 & 0.32 \\
\hline Netherlands & $0.02 * *$ & 0.46 & 0.38 & 0.69 & 0.83 & 0.53 \\
\hline Poland & $0.02 * *$ & 0.46 & 0.38 & 0.69 & 0.83 & 0.53 \\
\hline Slovakia & 0.43 & 0.12 & $0.038^{* * *}$ & 0.97 & 0.46 & 0.14 \\
\hline Slovenia & 0.79 & 0.18 & $0.002^{*}$ & 0.99 & 0.21 & 0.91 \\
\hline Spain & 0.27 & 0.88 & $0.056^{* *}$ & $0.068^{*}$ & 0.75 & 0.57 \\
\hline Sweden & $0.004 * * *$ & 0.83 & 0.24 & $0.059^{*}$ & 0.64 & 0.68 \\
\hline UK & 0.44 & 0.97 & 0.35 & $0.073^{*}$ & 0.38 & 0.93 \\
\hline
\end{tabular}

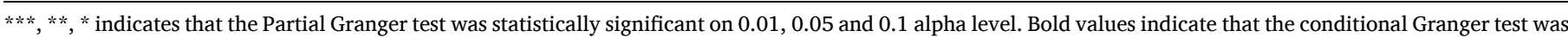
statistically significant on the 0.05 alpha level. Values in italics are statistically significant at the 0.1 alpha level (conditional Granger test).

root of MSE and MAPE. Columns Low and Upp contains several real values outside of the predictive confidence interval. Low indicates observations which were below the low boundary.

In total we have recorded 42 errors outside of the interval estimate. This represents an $18.25 \%$ error rate, which is higher than the expected $10 \%$ given the $90 \%$ confidence intervals. This elevated error rate is most likely caused by serious changes in some economics. The worst case is the Lithuania, where the car registrations increased over the expected level in recent years. This is documented in Fig. 4. The high error rate of Ireland is caused by increased seasonality. This high volatility was captured by the model and confidence intervals were appropriately enlarged. Thus, despite a high value of MAPE, predictions do not fall outside of the predictive confidence intervals.

A set of cumulative orthogonalized impulse response function from the seasonal VAR models is constructed to answer the third research question: "How does the car registrations react to the changes in selected predictors in the short-term?". Figs 5, 6 and 7 present a cumulative effect of one standard deviation change of the predictor value on car registrations.

Car registrations react to the change in the unemployment rate differently. In Slovakia and Ireland, the volume of car registrations decreases over time as the unemployment rate increases in the first month. In the Czech Republic and Germany is also expected to have a decline in registrations. However, due to the width of confidence intervals that span both positive and negative values, we cannot claim that the effect is proven. In this situation, policymakers know what the expected boundaries of good/bad scenario are.

The following set of orthogonalized response functions follows the same logic and the case of unemployment. Interestingly, countries react differently to some shock. Consider the Registrations 2 for the Czech Republic and Slovakia in Fig. 6. If there is an increased level of registrations in Germany, the number of cars registered in the Czech Republic decreases while in Slovakia number of registration increase. It would require a detailed analysis of potential causes which is out of the scope of this paper.

A shock of one standard deviation increase of public transportation 
Table 5

Statistically significant predictors in each VAR model.

\begin{tabular}{|c|c|c|c|c|c|c|c|}
\hline Country & Unemployment & Registrations2 & Inflation & Sentiment & Short-Term & Fuel & Registration \\
\hline Austria & $* * *$ & & & & & & $* *$ \\
\hline Belgium & $* *$ & & & & * & & \\
\hline Czech Republic & & & & & & & $* * *$ \\
\hline Denmark & & & & $* * *$ & & & $* * *$ \\
\hline Estonia & $* * *$ & & $* * *$ & $* *$ & & & $* *$ \\
\hline \multicolumn{8}{|l|}{ Finland } \\
\hline France & $* *$ & & & & & & $* * *$ \\
\hline Germany & & $* *$ & & $* *$ & $* *$ & & \\
\hline Greece & & & & $* *$ & & $* * *$ & $* * *$ \\
\hline \multicolumn{8}{|l|}{ Ireland } \\
\hline Italy & & $* *$ & & & & $* *$ & $* * *$ \\
\hline Latvia & & & & & & & $* * *$ \\
\hline Lithuania & & & & & $* *$ & & $* * *$ \\
\hline \multicolumn{8}{|l|}{ Luxembourg } \\
\hline Netherlands & $* *$ & & & & & & \\
\hline Poland & & & & & & & $* * *$ \\
\hline Slovakia & * & & & & & & $*$ \\
\hline Slovenia & & & & & & & $* * *$ \\
\hline Spain & & $* * *$ & & & & & $* * *$ \\
\hline Sweden & & $* * *$ & $* * *$ & & & & $* * *$ \\
\hline United Kingdom & & $* * *$ & $*$ & & & & \\
\hline
\end{tabular}

$* * *, * * *$ indicate that the factor was found statistically significant at $0.01,0.05$ and 0.1 alpha level.
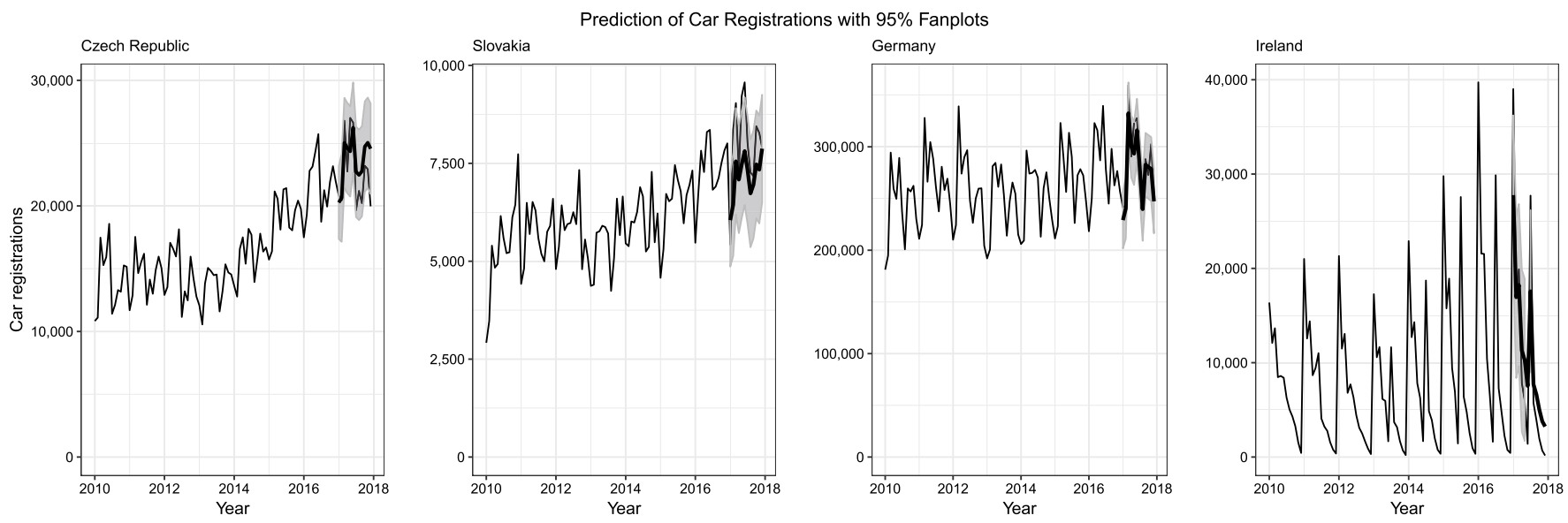

Fig. 3. Prediction for the 2017 values based on the seasonal VAR model.

costs has virtually no instantaneous effect on car registrations in the Czech Republic as seen from Fig. 7. It can be expected that there will be a small increase (125 more registered cars up to 4 months). However, estimated confidence intervals contain 0 , which indicate that the effect is not statistically significant. On the contrary, the effect of rising public cost is positive on car registrations in Germany. An overall effect flattens at the level of 4000 new registered cars.

\section{Conclusion}

Three research questions were stated in the Introduction. The first research question concerns the short- and medium-term patterns. From the visual analysis of the car registrations time series, we cannot distinguish prevailing medium-term patterns over the studied countries. Even though neighbouring countries went through the same economic cycle (perhaps except Poland), overall country-specific trends varied considerably. Some countries have experienced the U-shape of car registrations, while some grew throughout the period. Some countries stay at the level and do not increase/decrease the number of registrations. On the other hand, a seasonal pattern is present in all series. We can distinguish between two types of countries based on the registration tendencies towards the end of the year.

The second research question (existence of universal factors and indicators) was answered with mixed results. According to the first analysis of partial Granger tests, unemployment rate, car registrations in the strongest export country and cost of public transport were identified as the most relevant. Variable coefficients of the forecasting model tend to prefer past values of the domestic registrations. Unemployment rate and car registrations in the strongest export country were identified in several other countries, too. Public transportation costs and prices of fuel were absent from the important variable list in most of the analysed countries. We have received mixed results in different countries about the influence of household sentiment on car registration. Changes in short-term interest rates do not have predictive power in most countries. The relevance of analysed factors was confirmed by the predictive ability of the models, which was assessed by various indicators (MSE, MAPE and number of predictions outside of the predictive confidence interval).

The third research question concerned the direct and permanent effects of change. We have conducted an analysis of cumulative orthogonal impulse response functions. We have shown on the selected countries (the Czech Republic, Slovakia, Germany and Ireland) that car registrations do react in the same direction. Estimated irf were accompanied by bootstrapped confidence intervals that can help analysts and policymakers to estimate a possible range of effects.

The analysis we made does not provide a simple fit-it-all solution. It 
Table 6

Performance statistics of forecasting models. We present square root or MSE as it has a natural unit (number of vehicles).

\begin{tabular}{llllll}
\hline Country & $\sqrt{\text { MSE }}$ & MAPE & Low & Upp & Seas Strength \\
\hline Austria & 4193.30 & $12.6 \%$ & 0 & 5 & $88.1 \%$ \\
Belgium & 4884.23 & $9.5 \%$ & 0 & 0 & $88.2 \%$ \\
Czech Republic & 2226.24 & $8.6 \%$ & 1 & 0 & $71.9 \%$ \\
Denmark & 3156.76 & $13.1 \%$ & 0 & 3 & $61.7 \%$ \\
Estonia & 305.25 & $11.6 \%$ & 0 & 4 & $81.6 \%$ \\
Finland & 1142.48 & $9.9 \%$ & 0 & 0 & $52.8 \%$ \\
France & $15,946.42$ & $7.4 \%$ & 0 & 0 & $90.7 \%$ \\
Germany & $15,779.11$ & $4.4 \%$ & 0 & 1 & $90.8 \%$ \\
Greece & 1868.82 & $21.9 \%$ & 0 & 1 & $57.8 \%$ \\
Italy & 5319.67 & $12.3 \%$ & 0 & 2 & $89.4 \%$ \\
Ireland & $25,454.87$ & $272.0 \%$ & 0 & 2 & $89.0 \%$ \\
Latvia & 151.50 & $8.8 \%$ & 0 & 0 & $48.1 \%$ \\
Lithuania & 469.05 & $18.4 \%$ & 0 & 9 & $66.5 \%$ \\
Luxembourg & 526.25 & $10.5 \%$ & 0 & 2 & $91.2 \%$ \\
Netherlands & 5542.44 & $15.7 \%$ & 0 & 0 & $51.4 \%$ \\
Poland & 5001.88 & $11.5 \%$ & 5 & 0 & $70.4 \%$ \\
Slovakia & 1121.56 & $11.1 \%$ & 0 & 4 & $62.1 \%$ \\
Slovenia & 546.91 & $8.6 \%$ & 0 & 1 & $90.8 \%$ \\
Spain & 6246.28 & $5.7 \%$ & 0 & 0 & $89.6 \%$ \\
Sweden & 5393.14 & $15.8 \%$ & 2 & 0 & $89.8 \%$ \\
United Kingdom & $55,139.73$ & $33.1 \%$ & 3 & 1 & $98.4 \%$ \\
\hline & & & & & \\
\hline & & & 0 & 0 \\
\hline
\end{tabular}

points to the difficulties and ambiguous results which might even contradict expectations grounded in the economic theory. Yet, models can still retain good predictive performance. One of the conclusions is that forecasting systems should be tailored to the country-specific.

This paper has several limitations. Perhaps the most important one is the problem of omitted variables. We acknowledge the fact that observed variables are only proxies for the true factors. Moreover, purchasing behaviour happens on the household/company level, not at the country-level, as is our analysis. Therefore, some key factors, especially psychological factors, cannot be obtained. Restrictions were also imposed on the data given the requirement of monthly data. Application of methods which allows an analysis of mixed-frequency data, such as Bridge equations, mixed-data sampling models or mixed-frequency VAR models, might be considered in future research. Another data-related limitation stems from the country-level of the analysis. Each country in our analysis is considered as a homogenous area although most countries are partitioned into regions of higher and lower GDP per capita, into rural and urban regions etc. Our analysis, which focuses on the aggregate values of car registrations, would certainly benefit if the data about the car type preference or sociodemographic factors would be available in more spatial detail. Also, according to the European Union legislation, Article 2 of the Value Added Tax directive European Union, 2006 a car is considered new if the following two conditions are met. A car must not have been used for more than six months, and total travel distance does not exceed $6000 \mathrm{~km}$. This definition allows car

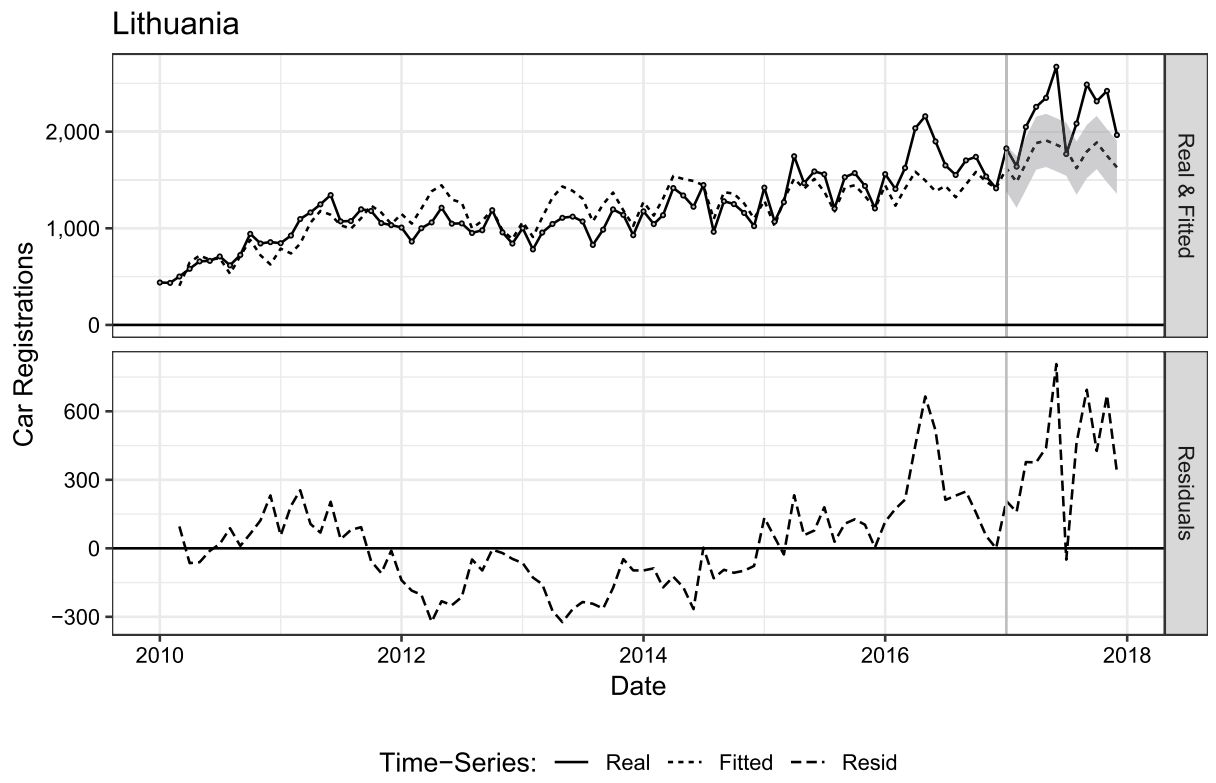

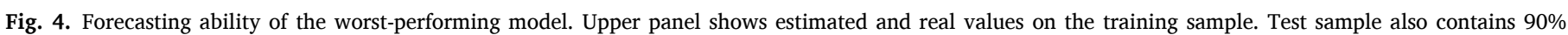
confidence interval. The bottom panel points to the increasing mean value of the residuals.
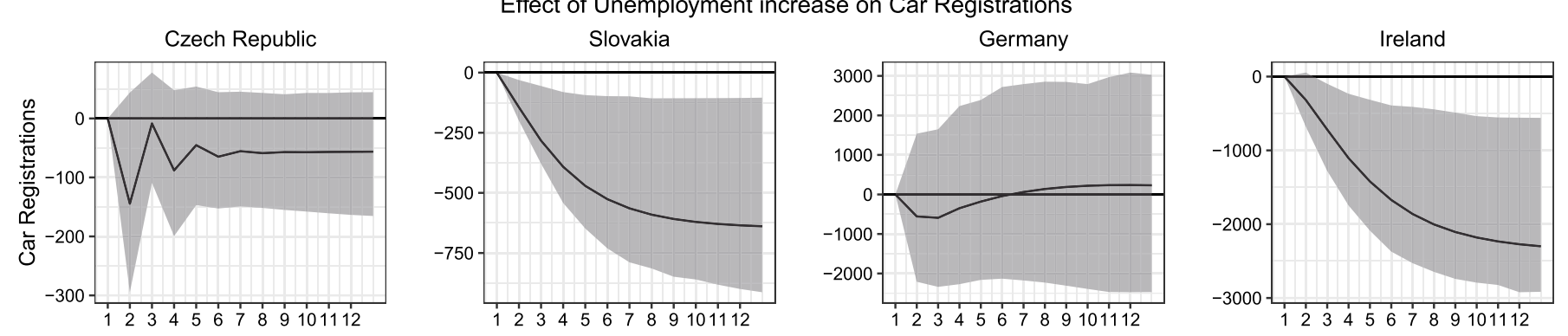

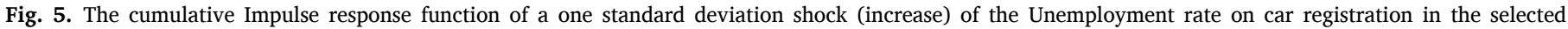
four countries. 


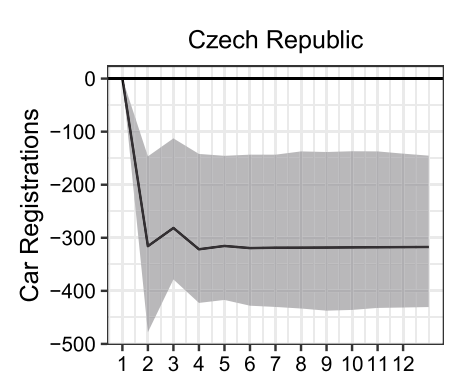

Effect of Car registration in export county increase on Car Registrations
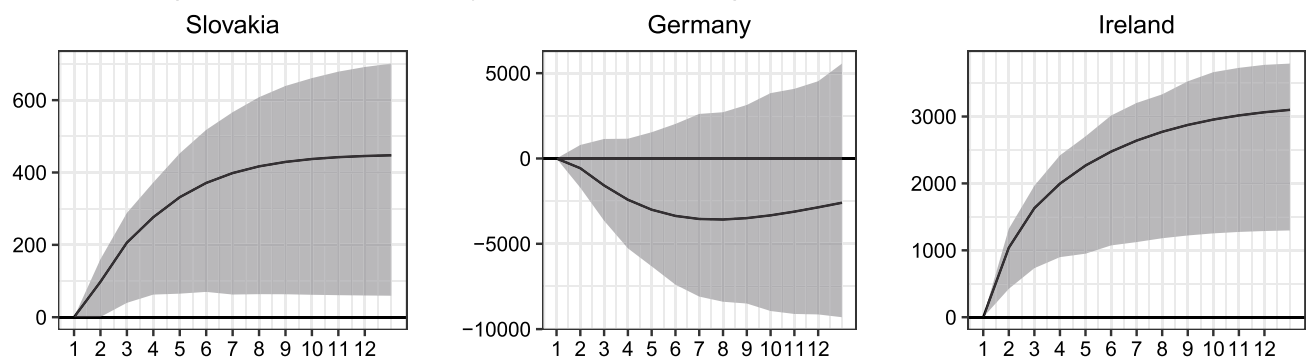

Fig. 6. The cumulative Impulse response function of a one standard deviation shock (increase) of the Car registrations in the strongest Export country.
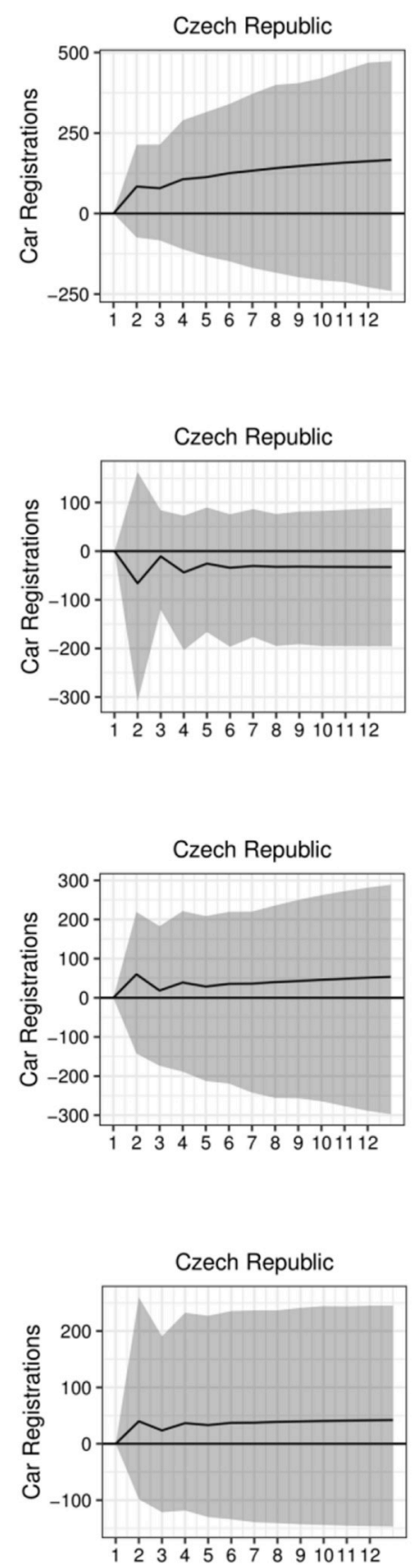

Effect of Public Transport Costs increase on Car Registrations
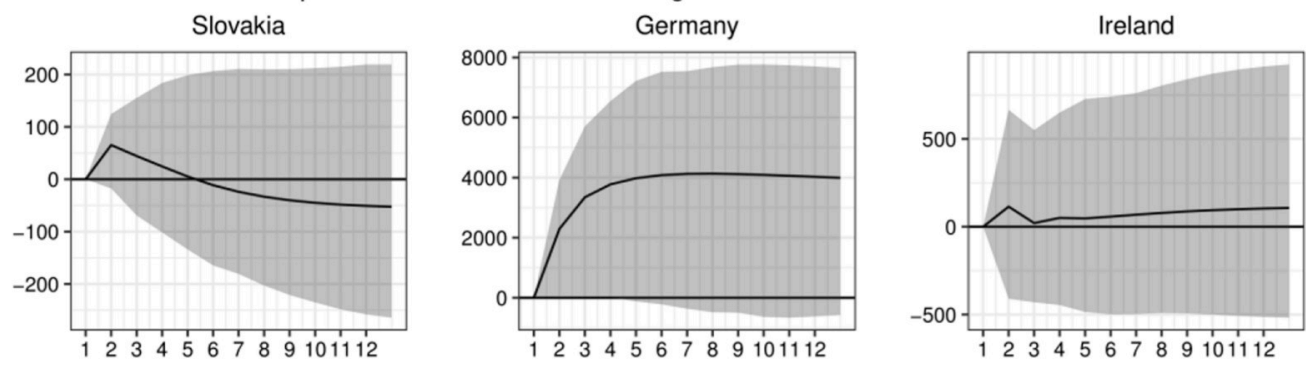

Effect of Sentiment ( $\mathrm{TCl}$ ) increase on Car Registrations
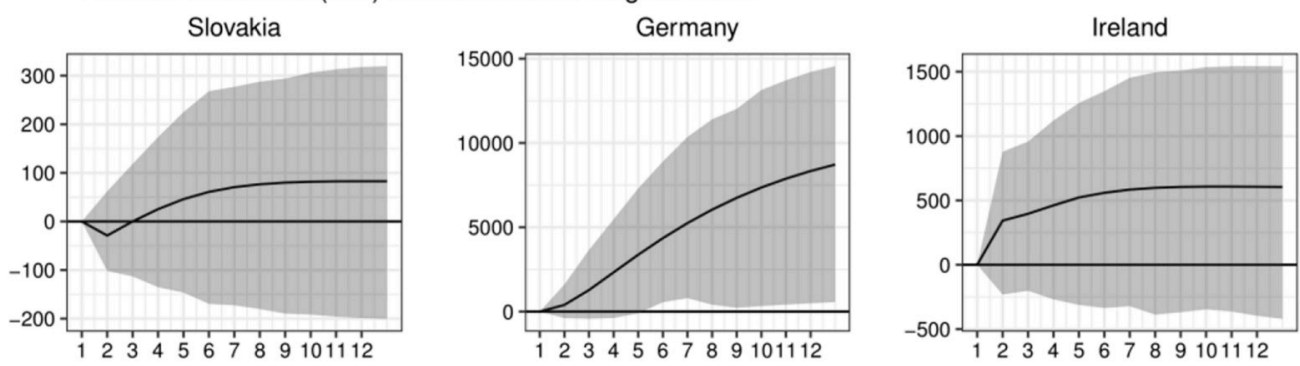

Effect of Short-term rate increase on Car Registrations
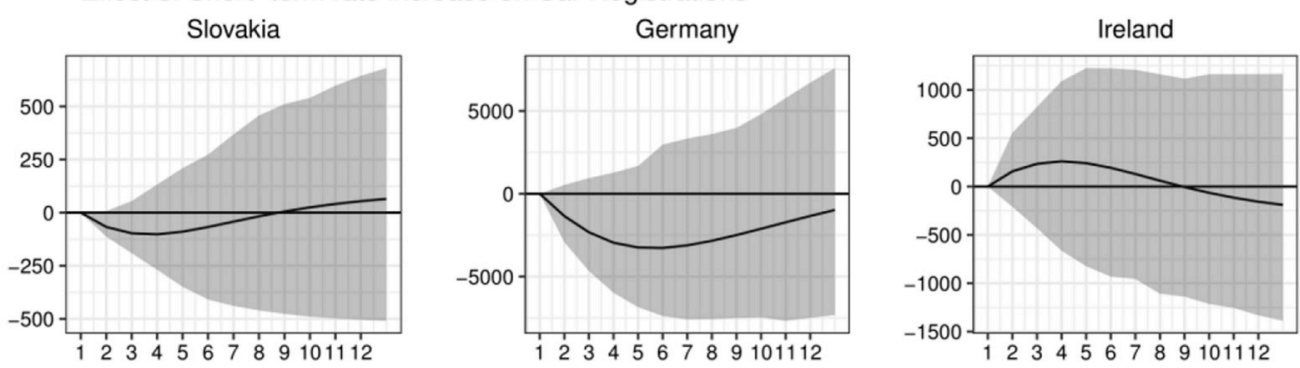

Effect of Fuel price rate increase on Car Registrations
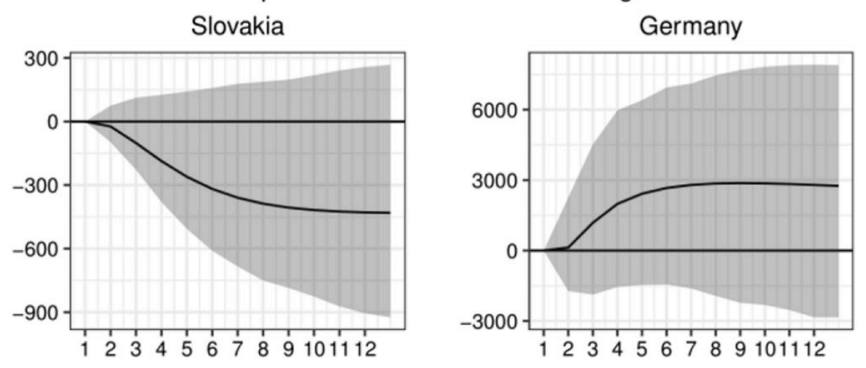

Fig. 7. Cumulative Orthogonal Impulse response functions for Public transportation costs, Total Confidence Indicator (sentiment), short-term interest rates and fuel prices. 
resellers to keep the new cars in stock for a longer period. This may cause an excessive sales due to promotion which later turn into increased car registrations. Moreover, it is a common practice to re-export cars within the car resellers from one country to another to benefit from the higher purchasing power of one country while keeping lower target prices for another.

Predicting at the country-level data allows adjusting for specific factors, such as a scrappage programme or governmental projects to support green energy. Although we can estimate the past effects of such an extraordinary event, it is questionable whether the magnitude of the effect will occur again in the future. Incorporation of knowledge about extraordinary measures or structural changes is a challenging and promising area for future research.

We have decided not to comment on a possible ad-hoc explanation for surprising results we have found have (e.g., a reason behind the drop of car registrations in the Czech Republic is the presence of car reexports to Germany from the Czech Republic. On the other hand, positive effects on Slovakian car registrations might be caused by transferred economic growth from Germany or the Eurozone). The added value of our paper lies in the identification of factors and different reactions of car registrations. As noted in the introduction, the purchase of a car is a big investment and requires cost-benefit thinking. It is interesting that short-term incentives cause registrations and can be successfully used for predicting.

The last restriction lies with the analytical methods available. The automotive sector produces goods which are traded on the international markets. It is challenging to capture the dynamics of such a system, even with recent analytical methods. This is even more difficult due to the missing information about the true value of registered cars in the light of the common practice of re-exports between dealers in countries with different purchasing powers. To make our analysis as much robust to overcome problems with confounders, we have applied a state-of-the-art approach to Granger causality tests in connection with the vector autoregressive model.

\section{Acknowledgment}

The authors are thankful for the financial support received from the Czech Science Foundation, Grant No. 16-25536S: Methodology of Developing a Predictive Model of Sector and Company Performance in the Macroeconomic Context.

\section{References}

ACEA. (2019). European automobile manufacturers' association (n.d.). Retrieved htt ps://www.acea.be/statistics/tag/category/employment-trends. (Accessed 29 December 2019).

Alberini, A., \& Bareit, M. (2019). The effect of registration taxes on new car sales and emissions: Evidence from Switzerland. Resource and Energy Economics, 56, 96-112. https://doi.org/10.1016/j.reseneeco.2017.03.005.

Alper, C. E., \& Mumcu, A. (2007). Interaction between price, quality and country of origin when estimating automobile demand: the case of Turkey. Applied Economics, 39(14), 1789-1796. https://doi.org/10.1080/00036840600707050.

Anowar, S., Eluru, N., Miranda-Moreno, L. F., \& Lee-Gosselin, M. (2015). Joint Econometric Analysis of Temporal and Spatial Flexibility of Activities, Vehicle Type Choice, and Primary Driver Selection. Transportation Research Record: Journal of the Transportation Research Board, 2495(1), 32-41. https://doi.org/10.3141/2495-04.

Bamberg, S., Fujii, S., Friman, M., \& Gärling, T. (2011). Behaviour theory and soft transport policy measures. Transport Policy, 18(1), 228-235.

Bouachera, T., \& Mazraati, M. (2007). Fuel demand and car ownership modelling in India. OPEC Review, 31(1), 27-51. https://doi.org/10.1111/j.14680076.2007.00175.x.

Bram, J., \& Ludvigson, S. C. (1998). Does consumer confidence forecast household expenditure? A sentiment index horse race. Economic Policy Review, 4(2).

Brand, C., Anable, J., \& Tran, M. (2013). Accelerating the transformation to a low carbon passenger transport system: The role of car purchase taxes, feebates, road taxes and scrappage incentives in the UK. Transportation Research Part A: Policy and Practice, 49, 132-148.

Brathwaite, T., \& Walker, J. (2018). Causal Inference in Travel Demand Modeling (and the lack thereof). Journal of Choice Modelling, 26, 1-18. https://doi.org/10.1016/j. jocm.2017.12.001.
Britton, E., Fisher, P. G., \& Whitley, J. D. (1998). Inflation report projections: Understanding the fan chart. Bank of England Quarterly Bulletin.

Buehler, R. (2011). Determinants of transport mode choice: A comparison of Germany and the USA. Journal of Transport Geography, 19(4), 644-657.

Cantos-Sánchez, P., Gutiérrez-i-Puigarnau, E., \& Mulalic, I. (2018). The impact of scrappage programmes on the demand for new vehicles: Evidence from Spain. Research in Transportation Economics, 70, 83-96. https://doi.org/10.1016/j.retrec.20 17.11.006.

Cervero, R., \& Kockelman, K. (1997). Travel demand and the 3Ds: Density, diversity, and design. Transportation Research Part D: Transport and Environment, 2(3), 199-219.

Chen, J., Esteban, S., \& Shum, M. (2010). Do sales tax credits stimulate the automobile market? International Journal of Industrial Organization, 28(4), 397-402.

Chng, S., White, M. P., Abraham, C., \& Skippon, S. (2019). Consideration of environmental factors in reflections on car purchases: Attitudinal, behavioural and sociodemographic predictors among a large UK sample. Journal of Cleaner Production, 230, 927-936. https://doi.org/10.1016/j.jclepro.2019.05.179.

Cleveland, R. B., Cleveland, W. S., McRae, J. E., \& Terpenning, I. (1990). Stl: A seasonaltrend decomposition procedure based on loess. Journal of Official Statistics, 6, 3-73.

Copeland, A. (2014). Intertemporal substitution and new car purchases. The RAND Journal of Economics, 45(3), 624-644.

Curl, A., Clark, J., \& Kearns, A. (2018). Household car adoption and financial distress in deprived urban communities: A case of forced car ownership? Transport Policy, 65, 61-71. https://doi.org/10.1016/j.tranpol.2017.01.002.

Dargay, J., \& Gately, D. (1999). Income's effect on car and vehicle ownership, worldwide: 1960-2015. Transportation Research Part A: Policy and Practice, 33(2), 101-138. https://doi.org/10.1016/S0965-8564(98)00026-3.

Dargay, J., Gately, D., \& Sommer, M. (2007). Vehicle ownership and income growth, worldwide: 1960-2030. Energy Journal, 28(4).

De Jong, G., Fox, J., Daly, A., Pieters, M., \& Smit, R. (2004). Comparison of car ownership models. Transport Reviews, 24(4), 379-408. https://doi.org/10.1080/ 0144164032000138733.

de Palma, A., \& Kilani, M. (2008). Regulation in the automobile industry. International Journal of Industrial Organization, 26(1), 150-167. https://doi.org/10.1016/j. ijindorg.2006.10.008.

Dees, S., \& Brinca, P. S. (2013). Consumer confidence as a predictor of consumption spending: Evidence for the United States and the Euro area. International Economics, $134,1-14$.

Easaw, J. Z., Garratt, D., \& Heravi, S. M. (2005). Does consumer sentiment accurately forecast UK household consumption? Are there any comparisons to be made with the US? Journal of Macroeconomics, 27(3), 517-532.

Eriksson, L., Nordlund, A. M., \& Garvill, J. (2010). Expected car use reduction in response to structural travel demand management measures. Transportation Research Part F: Traffic Psychology and Behaviour, 13(5), 329-342.

European Union, \& Council of the European Union.. (2006). Council Directive 2006/ 112/EC of 28 November 2006 on the common system of value added tax. Official Journal of the European Union, OJ L 347, 1-118. http://data.europa.eu/eli/dir/2006/ 112/oj, 2006. (Accessed 22 September 2019).

Eurostat. (2019). National accounts aggregates by industry (up to NACE A*64)[Datafile].

Ewing, R., \& Cervero, R. (2001). Travel and the built environment: A synthesis. Transportation Research Record: Journal of the Transportation Research Board, (1780), 87-114.

Fantazzini, D., \& Toktamysova, Z. (2015). Forecasting German car sales using Google data and multivariate models. International Journal of Production Economics, 170 , 97-135. https://doi.org/10.1016/j.ijpe.2015.09.010.

Gärling, T., Eek, D., Loukopoulos, P., Fujii, S., Johansson-Stenman, O., Kitamura, R., et al. (2002). A conceptual analysis of the impact of travel demand management on private car use. Transport Policy, 9(1), 59-70. https://doi.org/10.1016/S0967-070X (01)00035-X.

Gärling, T., \& Schuitema, G. (2007). Travel demand management targeting reduced private car use: Effectiveness, public acceptability and political feasibility. Journal of Social Issues, 63(1), 139-153.

Garner, C. A. (1991). Forecasting consumer spending: Should economists pay attention to consumer confidence surveys? Economic Review, 76(3), 57-71.

Garratt, A. (2012). Global and national macroeconometric modelling: A long-run structural approach. Oxford: Oxford University Press.

Ghysels, E., \& Marcellino, M. (2018). Applied Economic Forecasting Using Time Series Methods. Oxford, United Kingdom: Oxford University Press.

Greenspan, A., \& Cohen, D. (1999). Motor Vehicle Stocks, Scrappage, and Sales. Review of Economics and Statistics, 81(3), 369-383. https://doi.org/10.1162/ 003465399558300.

Leheyda, N., Grigolon, L., \& Verboven, F. (2016). Scrapping subsidies during the financial crisis - Evidence from Europe. International Journal of Industrial Organization, 44, 41-59. https://doi.org/10.1016/j.ijindorg.2015.10.004.

Gujarati, D. N., \& Porter, D. C. (2009). Basic econometrics. Boston: The McGraw-Hill.

Guo, S., Seth, A. K., Kendrick, K. M., Zhou, C., \& Feng, J. (2008). Partial Granger causality - eliminating exogenous inputs and latent variables. Journal of Neuroscience Methods, 172(1), 79-93. https://doi.org/10.1016/j.jneumeth.2008.04.011.

Haugh, D., Mourougane, A., \& Chatal, O. (2010). The automobile industry in and beyond the crisis. OECD Economic Outlook, 2009(2), 87-117. OECD economic outlook.

Hjorthol, R. (2016). Decreasing popularity of the car? Changes in driving licence and access to a car among young adults over a 25-year period in Norway. Journal of Transport Geography, 51, 140-146.

Huo, H., \& Wang, M. (2012). Modeling future vehicle sales and stock in China. Energy Policy, 43, 17-29. 
Hyndman, R., Wang, E., Talagala, T., Kang, Y., \& Yang, Y. (2018). tsfeatures: Time series feature extraction. R package version 0.1 . https://github.com/robjhyndman/tsfeatures \%.

Ingram, G. K., \& Liu, Z. (1999). Determinants of motorization and road provision. The World Bank.

Khoury, R. M. (2015). Do macroeconomic factors matter for stock returns? Evidence from the european automotive industry. International Journal of Monetary Economics and Finance, 8(1), 71.

Klein, N. J., \& Smart, M. J. (2017). Millennials and car ownership: Less money, fewer cars. Transport Policy, 53, 20-29.

Kloess, M., \& Müller, A. (2011). "Simulating the impact of policy, energy prices and technological progress on the passenger car fleet in Austria - a model based analysis 2010-2050. Energy Policy, 39(9), 5045-5062.

Konstantakis, K. N., Milioti, C., \& Michaelides, P. G. (2017). Modeling the dynamic response of automobile sales in troubled times: A real-time vector autoregressive analysis with causality testing for Greece. Transport Policy, 59, 75-81.

Lee, J., \& Cho, Y. (2009). Demand forecasting of diesel passenger car considering consumer preference and government regulation in South Korea. Transportation Research Part A: Policy and Practice, 43(4), 420-429.

Loukopoulos, P., Jakobsson, C., Gärling, T., Schneider, C. M., \& Fujii, S. (2004). Car-user responses to travel demand management measures: Goal setting and choice of adaptation alternatives. Transportation Research Part D: Transport and Environment, 9 (4), 263-280.

Metz, D. (2012). Demographic determinants of daily travel demand. Transport Policy, 21, $20-25$.

Muhammad, F., Hussin, M. Y., Razak, A. A., Rambeli, N., \& Tha, G. P. (2013). The relationship between macroeconomic variables and passenger vehicle sales in Malaysia. Business and Economic Research, 3(2), 115. https://doi.org/10.5296/ber. v3i2.3881.

Nolan, A. (2010). A dynamic analysis of household car ownership. Transportation Research Part A: Policy and Practice, 44(6), 446-455. https://doi.org/10.1016/j.tra. 2010.03.018.

OECD. (2010). The automobile industry in and beyond the crisis. OECD Economic Outlook, 2009(2), 87-117. Paris https://doi.org/10.1787/eco outlook-v2009-2-3-en.

Pavelková, D., Homolka, L., Vychytilová, J., Ngo, V. M., Bach, L. T., \& Dehning, B. (2018). Passenger car sales projections: Measuring the accuracy of a sales forecasting model 1. Ekonomický časopis, 66(3), 227-249.
Peters, A., Gutscher, H., \& Scholz, R. (2011). Psychological determinants of fuel consumption of purchased new cars. Transportation Research Part F: Traffic Psychology and Behaviour, 14(3), 229-239. https://doi.org/10.1016/j. trf.2011.01.003.

Pfaff, B. (2008). Analysis of Integrated and Cointegrated Time Series with R. New York: Springer-Verlag.

Pierdzioch, C., Rülke, J., \& Stadtmann, G. (2011). Forecasting U.S. car sales and car registrations in Japan: Rationality, accuracy and herding. Japan and the World Economy, 23(4), 253-258.

Prieto, M., \& Caemmerer, B. (2013). An exploration of factors influencing car purchasing decisions. International Journal of Retail \& Distribution Management, 41(10), 738-764.

Redman, L., Friman, M., Gärling, T., \& Hartig, T. (2013). Quality attributes of public transport that attract car users: A research review. Transport Policy, 25, 119-127.

Ritter, N., \& Vance, C. (2013). Do fewer people mean fewer cars? Population decline and car ownership in Germany. Transportation Research Part A: Policy and Practice, 50, 74-85.

Ryan, L., Ferreira, S., \& Convery, F. (2009). The impact of fiscal and other measures on new passenger car sales and $\mathrm{CO} 2$ emissions intensity: Evidence from Europe. Energy Economics, 31(3), 365-374.

Sa-Ngasoongsong, A., Bukkapatnam, S. T., Kim, J., Iyer, P. S., \& Suresh, R. (2012). Multistep sales forecasting in automotive industry based on structural relationship identification. International Journal of Production Economics, 140(2), 875-887.

Schorfheide, F., \& Song, D. (2015). Real-time forecasting with a mixed-frequency VAR. Journal of Business \& Economic Statistics, 33(3), 366-380. https://doi.org/10.1080 /07350015.2014.954707.

Schwert, G. W. (1989). Why Does Stock Market Volatility Change Over Time? Journal of Finance, 44(5), 1115-1153. https://doi.org/10.1111/j.1540-6261.1989.tb02647.x.

Tanner, J. C. (1975). Forecasts of vehicles and traffic in great britain: 1974 revision, transport and road research laboratory report LR 650. Crowthorne: Transport and Road Research Laboratory.

Train, K. (1993). Qualitative choice analysis: Theory, econometrics, and an application to automobile demand. MIT Press.

Van Wee, B. (2015). Peak car: The first signs of a shift towards ICT-based activities replacing travel? A discussion paper. Transport Policy, 42, 1-3.

Wang, F. K., Chang, K. K., \& Tzeng, C. W. (2011). Using adaptive network-based fuzzy inference system to forecast automobile sales. Expert Systems with Applications, 38(8), 10587-10593. 